\title{
GESTÃo PEDAGÓGICA E QUALIDADE SOCIAL DA EDUCAÇÃO: CONTRIBUIÇÕES DA PESQUISA COLABORATIVA EM ESCOLAS DE SÃO CAETANO DO SUL
}

\author{
ROSA, Sanny Silva da ${ }^{i}$ \\ CAMPOS, Géssica Natáliaii \\ PADOVAN, Maria Isabeliii \\ UMEMURA, Vanessa Maria Vicente ${ }^{\text {iv }}$
}

\begin{abstract}
RESUMO
Este artigo discute possibilidades de enfrentamento da lógica hegemônica das políticas de resultado que afetam a gestão pedagógica da escola e modificam o próprio sentido da educação. O texto está organizado em três tópicos complementares: o primeiro discute o papel do gestor no contexto de políticas que apostam no binômio currículo-avaliação como referência do conceito de qualidade do "novo" serviço público; o segundo problematiza os argumentos da alegada responsabilidade do coordenador pedagógico na formação continuada de professores no âmbito da escola; por fim, apresenta relatos de pesquisas colaborativas realizadas com profissionais de ensino do município de São Caetano do Sul, São Paulo, como forma de resistência e de alternativa contra hegemônica ao modelo produtivista de gestão. A partir de contribuições das teorias críticas de educação, aponta-se a necessidade de ocupar os espaços e os tempos possíveis no cotidiano escolar para recuperar o protagonismo dos professores e fortalecer o princípio da gestão democrática tendo em vista a qualidade social da educação.
\end{abstract}

PALAVRAS-CHAVE: Gestão pedagógica. Qualidade social da educação. Pesquisa colaborativa. São Caetano do Sul.

\footnotetext{
i Doutora em Educação (Currículo) pela PUC-SP, professora e pesquisadora do Programa de Mestrado Profissional em Educação da Universidade Municipal de São Caetano do Sul (USCS). Líder do grupo de pesquisa: Gestão Democrática e Qualidade Social da Educação Básica - USCS. E-mail: sanny.rosa@ @rof.uscs.edu.br ii Professora do Ensino Fundamental da Rede Municipal de São Caetano do Sul. Mestre em Educação pela USCS (Universidade Municipal de São Caetano do Sul).E-mail: gessicanatalia@ hotmail.com

iii Professora e coordenadora pedagógica do Ensino Fundamental II da Rede Municipal de São Caetano do Sul. Mestre em Educação pela USCS (Universidade Municipal de São Caetano do Sul). E-mail: mbel_pp@hotmail.com

iv Professora e assistente de direção na rede municipal de São Caetano do Sul. Mestre em Educação pela USCS (Universidade Municipal de São Caetano do Sul). E-mail: vanessaumemura.leandroklein@gmail.com
} 


\title{
CONTRIBUTIONS FROM THE COLLABORATIVE RESEARCH WITHIN SCHOOLS OF SÃO CAETANO DO SUL
}

\author{
ROSA, Sanny Silva dav \\ CAMPOS, Géssica Natália ${ }^{v i}$ \\ PADOVAN, Maria Isabel ${ }^{\text {vii }}$ \\ UMEMURA, Vanessa Maria Vicente viii $^{\text {vic }}$
}

\begin{abstract}
This paper discusses possibilities of confronting the hegemonic logic of results-oriented policies which affect the school pedagogical management and change the very meaning of education. The text is organized in three complementary topics: the first discusses the role of the manager in the context of policies that focus on the curriculum-assessment binomial as reference to the concept of quality for the "new" public service; the second challenges the argument of the alleged responsibility of the head teacher in the continuing education of teachers within schools; finally, it reports three collaborative researches carried out with teaching professionals in the municipality of São Caetano do Sul, São Paulo, Brazil, as form of resistance and counter-hegemonic alternative to the productivist model of management. Upon contributions from critical theories of education, it is pointed out the need to occupy the available spaces and times of the school routine to rescue the protagonism of teachers and to strengthen the democratic management principle for the sake of the social quality of education.
\end{abstract}

KEYWORDS: Pedagogical management. Social quality of education. Collaborative research. São Caetano do Sul.

\footnotetext{
${ }^{\mathrm{V}} \mathrm{PhD}$ in Education (Curriculum) by PUC-SP, teacher and researcher of the Professional Master's Program in Education of the Municipal University of São Caetano do Sul (USCS). Leader of the research group: Democratic Management and Social Quality of Basic Education - USCS. E-mail: sanny.rosa@prof.uscs.edu.br

${ }^{v i}$ Teacher of Elementary School of the Municipal Network of São Caetano do Sul. Master in Education by USCS (Municipal University of São Caetano do Sul).E-mail: gessicanatalia@hotmail.com

vii Teacher and pedagogical coordinator of Elementary Education II of the Municipal Network of São Caetano do Sul. Master in Education by USCS (Municipal University of São Caetano do Sul). E-mail: mbel_pp@hotmail.com

viii Teacher and assistant director in the municipal network of São Caetano do Sul. Master in Education by USCS (Municipal University of São Caetano do Sul). E-mail: vanessaumemura.leandroklein@gmail.com
}

Sanny Silva da ROSA, Géssica Natália CAMPOS, Maria Isabel PADOVAN, Vanessa Maria Vicente UMEMURA Gestão pedagógica e qualidade social da educação: contribuições da pesquisa colaborativa em escolas de São Caetano do Sul 


\section{INTRODUÇÃO}

Os efeitos (perversos) das políticas de educação orientadas por resultados sobre o currículo, sobre a gestão escolar e sobre o trabalho docente vêm sendo anunciados (e denunciados) já há algum tempo. Dado que se tornaram hegemônicas a partir das reformas do Estado, intensificadas na última década do século $\mathrm{XX}$, críticas a essas políticas ecoam em diferentes continentes pela voz de pesquisadores que se tornaram referência no campo da Educação brasileira, como Michael Apple (2014, 2018), José Gimeno Sacristán (2007), Stephen Ball (2008, 2012), Antônio Nóvoa (2009), apenas para citar alguns.

Entre nós, encontramos a mesma ordem de preocupações. Estudos recentes, como os de Hypolito, Vieira e Leite (2012), Chizzotti e Ponce (2012), Ponce e Rosa, (2014), Cóssio (2015) e inúmeros outros já apontaram as implicações de tais políticas sobre a dimensão intelectual do trabalho dos professores. Além disso, o imperativo de elevar os índices de desempenho dos alunos nas avaliações de larga escala consome grande parte do tempo e da energia dos profissionais da escola em atividades burocráticas e administrativas que não necessariamente se convertem em melhoria da qualidade da educação e do ensino (GARCIA; ANADON, 2009; BONAMINO; SOUSA, 2012).

Pesquisas demonstram que a ênfase curricular nos processos estritamente cognitivos desvia as ações da escola de sua dimensão propriamente educativa e empobrece a formação inicial e continuada de professores (SHIROMA, 2011; FREITAS, 2014). Em suma, está mais do que claro que esse conjunto de fatores contribui para restringir os mecanismos e as práticas de gestão democrática das instituições escolares, além de negligenciar a função social da escola.

Tendo esse cenário como pano de fundo, o presente artigo discute as possibilidades de enfrentamento dessa lógica hegemônica, por meio de práticas colaborativas que engajem os professores na gestão pedagógica do trabalho escolar. Operamos, aqui, na perspectiva de ampliação do conceito de qualidade na direção de uma qualidade social da educação. Esse conceito vem se consolidando com base em experiências que articulam os processos reflexivos e participativos da comunidade escolar com as preocupações e atividades de pesquisa realizadas pelos atores escolares em parceria com a universidade (SORDI; VARANI; MENDES, 2017). 
Com este texto, pretendemos compartilhar indagações e reflexões sistematizadas em pesquisas conduzidas na Rede Municipal de Ensino de São Caetano do Sul, localizado no Grande ABC Paulista, no estado de São Paulo, no âmbito de um programa de Mestrado Profissional em Educação. $\mathrm{O}$ objetivo comum desses trabalhos foi contribuir para o fortalecimento do princípio da gestão democrática, por meio do engajamento dos profissionais com um projeto de escola comprometido com a qualidade social da educação.

Para tanto, mais do que uma metodologia de pesquisa, a opção por realizar um trabalho colaborativo com os sujeitos diretamente envolvidos nas práticas escolares diz respeito ao pressuposto político e epistemológico que fundamenta o projeto do grupo*: o de que os professores não são "usuários" dos saberes produzidos pelas pesquisas, mas necessariamente coprodutores desses conhecimentos (IBIAPINA, 2008). Essa é, a nosso ver, a condição sine qua non para que se reconheçam nas novas compreensões que vão sendo produzidas no processo reflexivo ao qual têm sido chamados a participar. Essa é também a condição para o seu genuíno engajamento na concretização de projetos que expressem as opções políticopedagógicas resultantes do esforço coletivo de pensar e propor alternativas às formas de pensar e fazer educação que se tornaram senso comum nas políticas públicas brasileiras.

Com o objetivo de discutir esse tema, organizamos este texto em três momentos complementares. No primeiro deles, discutimos o papel estratégico assumido pelo gestor no contexto das políticas de resultado que apostam no binômio currículo-avaliação como balizas do conceito oficial de "qualidade". No segundo, e a partir das contradições e das tensões vividas especialmente pelo coordenador pedagógico, problematizamos sua alegada função de responsável pela "formação" de professores "em serviço", tendo em vista a posição artificialmente vertical do cargo que ocupa em relação a seus pares; alternativamente, destacamos seu papel como coadjuvante e colaborador na busca de uma qualidade social da educação, entendida como bem público. Por fim, mais do que resultados das pesquisas, procuramos dar relevo aos procedimentos e aos processos colocados em movimento como forma de resistência e alternativa contra-hegemônica ao modelo produtivista de gestão pedagógica do serviço público.

\section{GESTOR: O HERÓI DO SERVIÇO PÚBLICO McDONALDIZADO}

Sanny Silva da ROSA, Géssica Natália CAMPOS, Maria Isabel PADOVAN, Vanessa Maria Vicente UMEMURA Gestão pedagógica e qualidade social da educação: contribuições da pesquisa colaborativa em escolas de São Caetano do Sul 
O título deste tópico alude às observações feitas por Stephen Ball (2008) no livro The Education Debate, onde o sociólogo e pesquisador inglês faz uma análise minuciosa sobre as "tecnologias" utilizadas nas reformas educacionais na era da knowledge economy (economia do conhecimento). Nesse trabalho, o autor demonstra, principalmente por meio da análise da retórica empregada em discursos e documentos oficiais, que o ideário das mudanças consideradas "necessárias" para a sociedade do século XXI é extraído do mundo da economia e dos negócios. Sobre isso muito já foi dito, e as diretrizes políticas emanadas da Organização para a Cooperação de Desenvolvimento Econômico (OCDE) são suficientemente conhecidas.

Interessa, aqui, determo-nos um pouco mais sobre a lógica da "nova" concepção de serviço público resultante das reformas do Estado no seio das quais se atribui um outro papel aos gestores. A palavra-chave que expressa essa concepção - já nem tão nova - é produtividade, como ilustra este pequeno trecho do discurso proferido, em 2001, pelo então primeiro ministro britânico Tony Blair, sobre as reformas do setor público defendidas pelo New Labour:

Devemos deixar os sistemas mudarem e se desenvolverem. As velhas estruturas monolíticas não o farão. Não podemos projetar mudanças e melhorias através de decreto burocrático. Daí o programa de reforma [...]. Não são nossos impostos e nossa posição fiscal que estão nos segurando como nação. É a produtividade e o estado dos nossos serviços públicos (BLAIR, 2001 apud BALL, 2008, p. 16, grifo nosso, tradução nossa).

A intenção do autor ao destacar esse trecho foi demonstrar que as reformas educacionais pretendidas faziam parte de um conjunto maior de mudanças do setor público e da maneira de conceber o papel e a função do Estado no contexto da economia globalizada. À educação não caberia papel secundário nesse projeto; ao contrário, tratava-se de elemento estratégico, pois,

[...] para prosperar na economia global do conhecimento, será importante mudar todo o sistema educacional para garantir uma ampla base de trabalhadores de conhecimento que entendam e usem essas tecnologias de informação. Esses trabalhadores são os fundamentos da economia do conhecimento (BLAIR, 2001 apud BALL, 2008, p. 16, tradução nossa).

A similaridade desse discurso com aquele proferido, em 1996, pelo então presidente brasileiro Fernando Henrique Cardoso já foi assinalada em outro trabalho (ROSA, 2012):

Quem não perceber que o mundo mudou e que, nesse novo mundo, as nações que não se organizarem para ter uma atitude bastante ativa ficarão excluídas, se equivoca. [...]. Isso implica uma profunda reorganização do Estado brasileiro, da sociedade brasileira, das empresas brasileiras, da universidade 
brasileira e do modo pelo qual nos preparamos para essa nova etapa (BRASIL, 1996, p. 158).

Estava implícita na mensagem do presidente a menção às reformas "necessárias" na educação brasileira que viriam a se consolidar com a aprovação da nova Lei de Diretrizes e Bases da Educação Nacional, em dezembro daquele mesmo ano.

As políticas educacionais implementadas daí em diante têm sido denominadas de neoliberais, termo que nem sempre é seguido de cuidadoso entendimento sobre seu significado, tampouco de suas transformações ao longo do tempo. Chamamos atenção para esse fato, pois, no caso brasileiro, o papel assumido pelo Estado aproxima-se mais do que Peck e Tickell (2002) denominam como terceira fase do neoliberalismo, caracterizado por medidas regulatórias do Estado e apoiadas (e, em muitos casos, formuladas) por parceiros terceirizados, representantes da iniciativa privada ${ }^{\dagger}$.

A face explícita do papel regulador do Estado brasileiro faz-se sentir nas políticas implementadas em torno do binômio currículo-avaliação: primeiro, com a difusão dos Parâmetros Curriculares Nacionais (PCN), em 1998; em seguida, com as mutações das políticas de avaliação de larga escala ocorridas ao longo dos anos 2000 (BONAMINO; SOUSA, 2012); e, mais recentemente, com definição da Base Nacional Comum Curricular (BNCC), cujo espírito e formato atendem às expectativas dos "reformadores empresariais" de manter o controle pedagógico do processo educativo (FREITAS, 2014).

A despeito das significativas diferenças de estilo adotadas pelos governos ao longo das últimas três décadas (PONCE; ROSA, 2014), é fato indiscutível que a centralização das políticas de avaliação e currículo tem garantido ao Estado brasileiro manter-se no controle de diretrizes inegociáveis que submetem a educação muito mais à lógica econômica (daí a ênfase no modelo de "competências" e "habilidades") do que às demandas sociais da população.

Compreendido o cenário no qual se situa o gestor, é possível entender melhor a razão pela qual Ball o considerou como o "herói cultural" do novo paradigma do serviço público (2008, p. 47). É ele quem, em última instância, no palco da escola, tem a responsabilidade de fazer com que todos, professores, funcionários e também alunos, sejam "produtivos". Seu papel é instilar a atitude e a cultura na qual os profissionais da escola se sintam pessoalmente responsáveis e comprometidos com os resultados. Essa tarefa é, no entanto, profundamente paradoxal, pois:

Sanny Silva da ROSA, Géssica Natália CAMPOS, Maria Isabel PADOVAN, Vanessa Maria Vicente UMEMURA Gestão pedagógica e qualidade social da educação: contribuições da pesquisa colaborativa em escolas de São Caetano do Sul 
De um lado, suas atribuições são frequentemente apresentadas como afastadas das formas burocráticas, centralizadas, de controle sobre o trabalho. As responsabilidades gerenciais são delegadas, a iniciativa e a resolução de problemas são altamente valorizadas. Por outro lado, novas formas muito diretas de vigilância e automonitoramento são implementadas, por exemplo, sistemas de avaliação, configuração de metas, comparações de resultados (BALL, 2008, p. 48, tradução nossa).

A tensão que sustenta esse paradoxo se refere à tática de "soltar e apertar simultaneamente", defendida, como lembra o autor, por dois "gurus" da administração de empresas ${ }^{\ddagger}$ tática assimilada pela "nova” administração pública. Eis aqui a característica fundamental que distingue o conceito moderno de gestão da noção clássica de administração, ambos advindos do universo corporativo. Essa diferença acarretou consideráveis implicações para o campo da Educação.

Drabach e Mousquer (2009), por exemplo, examinaram as teorizações de pensadores brasileiros acerca da administração escolar ao longo do século XX com o intuito de identificar as transformações históricas e culturais que estão na base das críticas ao modelo clássico de administração e na substituição dessa nomenclatura pela de gestão escolar. Ao retomarem os primeiros escritos sobre administração escolar, na década de 1930, as autoras refrescam nossa memória sobre o pensamento de pioneiros desse campo no Brasil, como Carneiro Leão, Quirino Ribeiro, Lourenço Filho e Anísio Teixeira. Sem deixarem de assinalar a adesão das primeiras teorizações à racionalidade científica das abordagens clássicas - aliás, as únicas disponíveis à época - várias passagens reproduzidas pelas autoras evidenciam o compromisso desses pensadores com o projeto republicano de educação expresso no Manifesto dos Pioneiros da Educação Nova.

Um ponto comum defendido por eles era que o administrador deveria ser um educador e um intelectual, conhecedor dos modos de vida de sua época, para que as estratégias administrativas atendessem "[...] antes de mais nada, a uma filosofia e a uma política de educação" (DRABACH; MOUSQUER, 2009, p. 263). A ideia de que administração escolar não seria um fim em si mesma, mas um meio para atingir os fins educacionais, realizados por pessoas, foi explicitamente defendida por Lourenço Filho; e o postulado de que a educação, privilégio de poucos no Brasil, deveria se estender a todos foi uma das principais bandeiras de Anísio Teixeira em sua trajetória como educador/administrador.

Não se trata aqui de fazer um retrospecto saudosista ou laudatório desses personagens, mas de perceber que o uso de certas terminologias mais esconde do que revela os propósitos a 
elas subjacentes em cada momento histórico. Parece claro que, apesar do termo "gestão" carregar um forte sentido relacionado às noções de democracia, descentralização e autonomia, em contraposição ao caráter tecnocrático, centralizador e autoritário associado à “administração", isso não significa que as práticas a eles correspondentes sejam coerentes com esses mesmos princípios.

Uma leitura crítica dos significados e dos sentidos atribuídos a essas noções, em cada momento histórico, não prescinde de uma atenta observação das práticas efetivamente postas em ação em cada caso. Se é verdade que, de acordo com as teorias clássicas, o administrador ocupava lugar central no planejamento e na condução das ações da escola, é também fato que dispunha de uma autonomia para julgar e tomar decisões que já não tem lugar no mundo estandardizado.

As profundas transformações tecnológicas e econômicas ocorridas nas últimas décadas do século XX e no início do século XXI alteraram radicalmente os modos de produção, as configurações do trabalho e, por consequência, a maneira de administrar no mundo globalizado. O paradigma do "novo" modelo assenta-se no fenômeno da McDonaldização (RITZER, 2010) dos sistemas de produção e entrega (delivery) de produtos e serviços. Para esse sociólogo, o sucesso do modelo McDonald's reside em quatro características básicas do negócio: eficiência (poder de produzir os resultados esperados); calculabilidade (ênfase nos aspectos quantitativos do "produto"); previsibilidade (padronização dos procedimentos de produção); e controle (mecanismos de monitoramento do desempenho das forças de trabalho envolvidas).

Contudo, o modelo McDonald's não se sustenta apenas nas forças do mercado, tão valorizadas pelos ideais liberais clássicos, mas antes em suas técnicas gerenciais. Aplicadas às políticas de educação, a burocracia centralizada do Estado define o produto e regula os padrões de qualidade esperados na entrega (delivery) dos serviços. Como o gerente de uma franquia, cuja autonomia se restringe à operação da unidade concedida, cabe ao gestor escolar administrar os insumos de que dispõe (infraestrutura, materiais didáticos, professores capacitados, etc.) para prestar contas dos serviços educacionais sob sua responsabilidade. Gary Wilkinson (2010, p. 154) afirma que a McDonaldização do sistema educacional se sustenta em mecanismos centralizados de elaboração de roteiros (script-writings) e medidas de controle de 
desempenho com os quais é possível assegurar que tanto o conteúdo como a forma de tratamento dos serviços sejam empregados de forma eficiente.

Fácil deduzir que os scripts de que fala o autor se materializam nas orientações e nos manuais curriculares que, minuciosamente, prescrevem o que deve ser ensinado e como devem ser ensinados os produtos (outputs) mais valorizados (pelo mercado). Vistos como sanduíches, cujos ingredientes e receitas não devem sofrer muitas variações entre uma lanchonete e outra a fim de manter o "cliente" satisfeito - o sonho dos formuladores das políticas delivery ${ }^{\S}$ é que os sistemas de ensino funcionassem, de fato, à moda de uma rede (franchising).

No caso brasileiro, mais do que a preocupação com a função social da escola, a obsessiva busca pela elevação dos indicadores de qualidade dos sistemas públicos de educação constitui estratégia de propaganda política dos grupos que disputam e se alternam no poder nas diferentes esferas administrativas. Daí a proliferação de sistemas próprios de avaliação de larga escala, organizados nos estados e nos municípios (BONAMINO; SOUSA, 2012), que contam com a fidelidade de seus gestores para entregar aos "clientes" (pais, eleitores e o próprio mercado de trabalho) a prometida "qualidade" de seus "serviços" educacionais. Trataremos desse tema no próximo tópico ao discutirmos, mais especificamente, o lugar ocupado pelo coordenador pedagógico nessa dinâmica.

\section{COORDENADOR PEDAGÓgICO: CO-LABORADOR OU O “OLHO” DO SISTEMA?}

Melhorar a qualidade do ensino é assunto que passa necessariamente pela formação de professores. A unanimidade construída em torno dessa ideia é tão evidente que a afirmativa se transformou em axioma a partir do qual diferentes teses são desenvolvidas por aqueles que visam encontrar "soluções" para os problemas da educação. Outro ponto consensual é que, no contexto escolar, a responsabilidade por essa tarefa é do coordenador pedagógico. A centralidade desse personagem na promoção das mudanças esperadas transformou-se, assim, em outro pressuposto inquestionável nos meios educacionais.

Repetidos à exaustão, tanto por forças progressistas como pelas mais conservadoras, tais consensos acabam por obscurecer as intencionalidades políticas que os sustentam. Colocálos em questão é justamente o que se pretende neste tópico: será mesmo que a melhoria da qualidade da educação e do ensino depende fundamentalmente de "mais" formação dos 
professores? E se esse é o caso, é responsabilidade do coordenador pedagógico "formar" o corpo docente da escola? E, o mais importante, que entendimento e que expectativas estão implícitas nos usos do termo "formação"? Ao fazermos tais questionamentos não estamos negando a necessidade de investir continuamente no desenvolvimento dos profissionais da educação, tampouco desconsiderando a importância do lugar ocupado pelo coordenador pedagógico. Antes, a intenção é colocar em questão os argumentos que sustentam essas teses.

A despeito das conhecidas fragilidades dos cursos de licenciatura (GATTI; BARRETO; ANDRÉ, 2011; MARIN; GIOVANNI, 2013), é também fato que as redes públicas contam (ainda) com muitos profissionais experientes e com saberes sólidos sobre o seu trabalho. Apesar disso, insiste-se na relação entre os baixos índices de desempenho dos alunos nas avaliações de larga escala e a "qualidade" dos professores, uma relação não apenas difícil de comprovar, mas também preocupante na medida em que a sustentação desse argumento desvia a atenção de outros fatores intervenientes na qualidade pretendida (BAUER, 2012). Ao colocar essa polêmica em foco, Adriana Bauer relembra as considerações de outra autora sobre o uso político dessa relação que, em absoluto, não é direta.

Não existe uma relação mecânica entre conhecimento do professor $e$ aprendizagem do aluno ou entre capacitação do professor e rendimento escolar: não se pode esperar que cada ano de estudos, cada curso ou oficina de capacitação resulte imediata e necessariamente em quantidades mensuráveis de aprendizagem (melhorada) por parte do alunado. Esta visão corresponde a uma percepção da educação e da aprendizagem escolar que equipara escola e fábrica e vê o ensino e a aprendizagem à luz do modelo fabril insumo-produto (inputs-outputs) (TORRES, 1998, p. 175, grifos da autora, apud BAUER, 2012, p. 71).

Para atualizar a imagem construída pela autora, diríamos que essa concepção se aproxima, hoje, mais do modelo McDonald's de gerir os serviços educacionais das políticas delivery de que falávamos. Isso porque grande parte dos programas de formação continuada adota formatos instrumentais, abrigados sob terminologias tipicamente empresariais (capacitação, treinamento, workshops) que não escondem a expectativa de que esses esforços se convertam em competências (ou performances) profissionais que tornem a escola mais "eficiente" e "eficaz".

Contudo, dado que essa fórmula, adotada há décadas pelos sistemas públicos de ensino - muitos por meio de parcerias com consultorias representantes do setor privado especializadas em "soluções educacionais" - parece não ter conseguido ainda alcançar a qualidade tão 
almejada, é legitimo que se indague: que intencionalidades justificam a insistência na tese sobre a necessidade de investir mais do mesmo na formação "em serviço" dos profisssionais de educação? E por que essa tarefa tem sido atribuída, no âmbito da escola, ao coordenador pedagógico, se não na esperança de que ele seja o "herói” que conseguirá replicar/multiplicar as "soluções" tidas como eficientes e eficazes?

Para romper com o círculo vicioso, cuja ineficácia (para usar um termo compreensível ao modelo empresarial no qual a fórmula se origina) se torna evidente, mas também para trilhar caminhos alternativos e contra-hegemônicos, o primeiro passo é ampliar a compreensão sobre o que faz (e o que deveria fazer) um coordenador pedagógico com o objetivo de encontrar outros e novos significados sobre o seu papel dentro da escola e junto a seus pares.

Se grande parte do processo de construção de sua identidade tem por base o que é dito sobre suas atribuições, não seria incorreto afirmar que esse personagem sofre de um grande mal-estar. Isso porque o coordenador pedagógico se vê dividido e impelido a atender expectativas provenientes de constructos teóricos e demandas concretas diametralmente conflitantes. De um lado, em algum momento de sua formação inicial, na universidade, foi convencido de que:

Um coordenador comprometido com seu papel de educador, cujos princípios da educação democrática constituem sua concepção do que deve ser a educação, investirá na construção de uma autoridade que exclui a coerção como meio de conquista, exercitando a responsabilidade, o auto-respeito, a autonomia. (SOUZA; PLACCO, 2009, p. 36).

De outro, no exercício cotidiano de sua profissão, muito provavelmente já se deparou com orientações similares às pronunciadas por esta dirigente de um programa curricular da rede estadual paulista:

[...] é claro que ele [o Coordenador Pedagógico] não vai fiscalizar as aulas, embora seja super recomendado que ele assista algumas e ele poderá monitorar o trabalho do professor para saber o que é que está acontecendo, o que está sendo ensinado, como se dão as relações sociais dentro da sala de aula, a relação entre os alunos, quais são os cuidados em relação às atitudes e valores que estão sendo veiculados, qual é a relação do professor com a sua classe, como estão sendo tratados os diferentes [...]. Não estou dizendo que o professor coordenador deve cuidar diretamente, mas ele tem que cuidar que os professores estejam cuidando. É este monitoramento, esta é a essência da função estratégica de mediação (FINI, 2009 apud TAVARES, 2012, p. 74).

Note-se que, para dar conta das expectativas dos órgãos centrais do sistema, o coordenador, como um bom gestor, precisaria estar convencido que monitorar os professores 
- e, portanto, exercer sim sobre eles uma força coercitiva - é a essência de seu trabalho; uma função estratégica para que o sanduíche não fuja aos padrões definidos pelos franqueadores desse serviço. É nesse sentido que os sistemas de ensino contam com a fidelidade do "bom gestor". E, para tanto, valem-se de discursos ideológicos, recheados de vocábulos como autonomia, participação, gestão democrática, descentralização que, há muito, se distanciaram dos ideais republicanos de Educação. Como esclarece o educador português, Licínio Lima:

[a] autonomia (mitigada) é um instrumento fundamental de construção de um espírito e de uma cultura da organização-empresa; a descentralização é congruente com a 'ordem espontânea' do mercado; respeitadora da liberdade individual e garante a eficiência econômica; a participação é essencialmente uma técnica de gestão, um fator de coesão e consenso. Assim, nesta perspectiva, conceitos como 'autonomia', 'comunidade educativa', 'projeto educativo', continuarão a ser convocados, e até com maior frequência, mas como instrumentos essenciais de uma política de modernização e racionalização [...] como resultados ou artefactos, e não como processos e construções coletivas (LIMA, 2002, p. 31).

A ambiguidade dos discursos que circulam nos meios educacionais confunde os educadores, levando-os, não raramente, a uma adesão involuntária a propostas que, em geral, não se conectam aos interesses e às necessidades de sua realidade local. Tornam-se, assim, e sem que se deem conta "intelectuais orgânicos" (PONCE; ROSA, 2014) de um projeto políticopedagógico cuja origem e destino desconhecem. Drabach e Mousquer (2009) afirmam que a perversidade verificada no campo da educação se situa exatamente na confluência destes dois projetos - o da gestão democrática e o da gestão gerencial - que, utilizando a mesma linguagem, têm como horizonte concepções distintas de educação e de seu significado social.

Enquanto, para o projeto democrático, a participação visa à construção de uma sociedade fundada na justiça social, na igualdade e na democracia, a perspectiva gerencial valoriza a participação como técnica de gestão. Para o projeto democrático, a educação é bem público a que todos têm direito como parte de sua condição humana e de integrantes da "vida ativa" da polis, no sentido arendtiano do termo. No projeto neoliberal e neotecnicista, ao contrário, a ação de educar caracteriza-se pelo "labor", esforço do corpo, atividade que "não requer a presença de outros" (ARENDT, 2001, p. 31) e se esgota quando cumpre a finalidade de preservação da vida biológica.

Para demarcar a diferença entre labor e trabalho, termos que na modernidade são entendidos como sinônimos, Hanna Arendt recorre à etimologia dessas palavras e nos explica 
que: “[...] a palavra <labor>, como substantivo, jamais designa o produto final, o resultado da ação de laborar; permanece como substantivo verbal, uma espécie de gerúndio. Por outro lado, é da palavra correspondente a trabalho que deriva o nome do próprio produto [...]" (ARENDT, 2001, p. 91).

Em A Condição Humana, a cientista política postulou essa distinção porque, enquanto o trabalho "[...] acrescenta novos objetos ao artifício humano, a produtividade do labor só ocasionalmente produz objetos" (ARENDT, 2001, p. 99). Tal compreensão, reminiscente da tradição grega, que via o labor como atividade servil, reaparece na modernidade por meio da distinção entre trabalho produtivo e improdutivo. É apenas com Marx que o labor é promovido e equiparado à categoria trabalho, explica Arendt (2001, p. 99), ao descobrir que a produtividade de qualquer atividade reside não no seu produto, mas no excedente produzido pelo trabalhador que é "mais do que o necessário à sua reprodução".

Com efeito, a pensadora insiste na distinção entre os termos, argumentando que enquanto o produto do labor se extingue no seu consumo, o produto e a finalidade do trabalho definem-se pela sua durabilidade, isto é, pela sua permanência na objetividade do mundo, para além do tempo que transcorre entre o nascimento e a morte do indivíduo. É nesse sentido que o resultado do trabalho é entendido como bem público.

O mundo das coisas feito pelo homem, o artifício humano construído pelo homo faber, só se torna uma morada para os homens mortais, um lar cuja estabilidade suportará e sobreviverá ao movimento continuamente mutável de suas vidas e ações, na medida em que transcende a mera funcionalidade das coisas produzidas para o consumo e a mera utilidade dos objetos produzidos para o uso (ARENDT, 2001, p. 187).

A retomada desses conceitos é crucial para a discussão sobre o papel do coordenador pedagógico, cujo trabalho (ou labor?) tem sido disputado por projetos que conflitam entre si. Abrimos esse tópico indagando se o coordenador seria um colaborador ou o "olho" do sistema. A pergunta sugere que a resposta poderia surgir facilmente do posicionamento entre duas alternativas claras e distintas. No entanto, a vida na escola não constitui um sistema binário. É muito mais complexa do que isso; é cheia de tensões, contradições, dissimulações, ambiguidades. A formulação da pergunta nesses termos é meramente provocativa às nossas reflexões.

Interessante notar que a palavra que substantiva a função de coordenar alude ao lugar de alguém que não está só, mas com outros, no papel de auxiliar, organizar, integrar e articular 
as partes de um todo. O prefixo " $c o$ ", em latim, significa estar ou realizar algo em conjunto, o que indica uma posição de simetria, de igualdade, e não a de alguém que está acima do grupo de que faz parte. No entanto, rigorosamente, as atribuições do coordenador pedagógico são menos análogas a de um maestro que rege a orquestra (FREIRE, 1996) e mais próximas a de um ator que, nas artes cênicas, atua em papel secundário. Seu papel é de co-adjuvante e colaborador, na medida em que precisa compreender o enredo para dar suporte aos protagonistas de um projeto comum.

E se, na escola, o que adjetiva esse projeto é o trabalho pedagógico, levado a termo pelos professores, a função do coordenador seria, no limite, tributária das ações destes últimos. Se a imagem faz sentido, depreende-se que a posição vertical do cargo que ocupa em relação a seus pares é fruto de uma cultura calcada em relações de poder historicamente construídas em torno da ideia de hierarquia e controle, que mira a conquista de sucessos individuais (o melhor aluno, a melhor escola, o melhor sistema de ensino), e não na noção de trabalho coletivo que entende a educação como bem público e como um direito de todos.

Em meio à ambiguidade dos discursos "consumidos" na escola - mecanismo ideológico, repetimos, necessário à reprodução da lógica produtivista hegemônica - não se trata de fazer uma opção entre realizar um trabalho colaborativo ou manter-se como "olho" do sistema. Isso porque não há opção ante a um projeto poderoso, desenhado com a intenção de reduzir a educação escolar a um objeto de troca no mercado de trabalho e combustível da economia global. Por outro lado, como bem colocado por Werle et al. (2012, p. 21), no contexto das práticas “[...] não estamos frente a um jogo inevitável de determinações, mas perante um campo de forças aberto a contradições”. Portanto, trata-se sim de oferecer resistência e abrir caminhos que possibilitem, de um lado, a elaboração de compreensões mais críticas sobre a intencionalidade de discursos e práticas que têm como alvo a fragilização da gestão democrática da escola; e, de outro, de fortalecer o protagonismo de seus atores na definição e no controle do seu projeto político-pedagógico tendo em vista uma qualidade social da educação.

No próximo tópico, ao apresentarmos a experiência de coordenadores pesquisadores do município de São Caetano do Sul, procuramos dar relevo aos procedimentos e aos processos colocados em movimento na tentativa de descortinar possibilidades de instituir práticas contra- 
hegemônicas e de resistência ao modelo produtivista de gestão pedagógica em contextos em que o exercício democrático constitui um dos maiores desafios dessa rede.

\section{PRÁticas COLAborativas de GeStão PEDAGógica: O PALCO DAS PESQUISAS}

Conhecida como "berço" da indústria automobilística do país, a região do Grande ABC Paulista enfrenta uma série de problemas socioeconômicos resultantes, em grande medida, das profundas transformações do mundo do trabalho e da cultura ocorridas a partir das duas últimas décadas do século XX. Ainda assim, trata-se de uma das regiões mais ricas e desenvolvidas do país.

Considerando os resultados do Índice de Desenvolvimento da Educação Básica (IDEB), obtidos entre 2005 e 2011, verifica-se que, em geral, os municípios vêm cumprindo as metas projetadas nas últimas avaliações nacionais, apesar do desempenho ser considerado "preocupante" nos anos finais do Ensino Fundamental por permanecer estagnado "e bem abaixo da meta estabelecida pelo Inep", conforme dados do Observatório da Educação da Região do Grande ABC Paulista (GARCIA et al., 2015a, p. 60).

No que se refere à "gestão democrática", o estudo citado constatou que, nos municípios do Grande ABC, esses " [...] ideais estão mais consolidados no papel e no discurso do que na concretude do cotidiano" (GARCIA et al., 2015b, p. 178). E não só pela forma de escolha dos diretores e coordenadores pedagógicos (em geral feita por indicação política ou técnica), mas também pela participação incipiente da comunidade (pais, professores e alunos) nos processos decisórios da escola Apesar de existirem formalmente os canais de participação (conselho escolar, conselho de classe, etc.), os mecanismos pelos quais são acionados evidenciam inconsistências que fragilizam a gestão democrática.

Essa realidade é ainda mais evidente no município de São Caetano do Sul “[...] onde o clientelismo é parte da constituição histórica, social e política da cidade" (GARCIA et al., 2015b, p. 177). Não surpreende, portanto, que concentre as escolas mais centralizadoras e as que menos criam possibilidades de participação da comunidade escolar, de acordo com o mesmo estudo.

Para os padrões brasileiros, São Caetano é um município rico, posicionado, segundo o IBGE (2016), no 49 lugar na constituição do Produto Interno Bruto (PIB) do país e ostenta, 
com orgulho, o primeiro lugar no ranking nacional do Índice de Desenvolvimento Humano Municipal (IDHM) conquistado em 2010.** Em seus restritos $15,33 \mathrm{~km}^{2}$, que fazem fronteira com as cidades de São Paulo, Santo André e São Bernardo do Campo, vivem atualmente 150.860 habitantes (FUNDAÇÃO SEADE, 2017). A rede pública de educação é composta por 20 escolas municipais que atendem a 13.500 alunos nos Ensinos Fundamental e Médio.

$\mathrm{Na}$ etapa inicial desta pesquisa, foi feito o levantamento do perfil profissional e de formação de 14 coordenadores pedagógicos das escolas que atendem os anos finais do Ensino Fundamental. Alguns achados confirmam características já identificadas em estudos de maior abrangência (GATTI; BARRETO; ANDRÉ, 2011) sobre os profissionais de educação: a forte predominância das mulheres (83\%); faixa etária entre 30 e 54 anos (100\%); formação inicial em Pedagogia (58,3\%), realizada em instituições privadas de Ensino Superior (83\%); com experiência consolidada como docentes (50\% deles entre 16 e 20 anos ou mais).

Utilizando como matriz algumas questões do questionário do Gestor da Prova Brasil 2013, foram mapeadas as atividades que mais ocupam os coordenadores no dia a dia das escolas do município. Os dados mostram que as atividades que tomam a maior parte de seu tempo não se relacionam à proclamada função primordial do coordenador: a formação continuada de professores e a gestão do trabalho pedagógico da escola.

Os quadros apresentados a seguir apontam aquelas tarefas que sempre ocupam a sua rotina de trabalho. A leitura e a interpretação desses números tornam-se mais significativas quando cotejadas com as falas desses sujeitos acerca das dificuldades, dos desafios e dos prazeres associados ao seu trabalho.

Quadro 1 - Rotina de trabalho relacionada aos alunos

\begin{tabular}{|l|c|}
\hline \multicolumn{1}{|c|}{ Rotina de trabalho relacionada aos alunos } & Sempre \\
\hline Resolve casos de indisciplina/ conflito dos alunos. & $75 \%$ \\
\hline Atende aos alunos. & $75 \%$ \\
\hline Atende aos professores. & $100 \%$ \\
\hline Atende aos pais de alunos. & $83 \%$ \\
\hline Acompanha a rotina da escola (entrada, intervalos e saída dos alunos). & $75 \%$ \\
\hline Participa do trabalho de inclusão de alunos com necessidades especiais. & $58 \%$ \\
\hline $\begin{array}{l}\text { Organiza e acompanha atividades extracurriculares (saídas pedagógicas, } \\
\text { festas, projetos, mostras, campanhas, etc.). }\end{array}$ & $67 \%$ \\
\hline Substitui professores e/ou outros membros da equipe gestora. & $42 \%$ \\
\hline
\end{tabular}

Fonte: Elaborado pelas autoras.

Sanny Silva da ROSA, Géssica Natália CAMPOS, Maria Isabel PADOVAN, Vanessa Maria Vicente UMEMURA Gestão pedagógica e qualidade social da educação: contribuições da pesquisa colaborativa em escolas de São Caetano do Sul 
Embora a tarefa de "atender aos professores" apareça como central na rotina do coordenador pedagógico (CP), os dados evidenciam que essa atenção se dispersa entre inúmeras outras demandas que continuamente se impõem no cotidiano da escola. As urgências do dia a dia se traduzem na falta de tempo para cuidar do que lhes parece essencial e é fator gerador de ansiedade e de frustração, como ilustra o depoimento que segue de uma coordenadora pedagógica:

"O tempo é um fator complicado, pois são muitas coisas para dar conta ao mesmo tempo e sinto que, por isso, não consigo fazer o melhor trabalho possível. Além disso, as funções burocráticas e os momentos que precisa "apagar os incêndios" tomam o tempo que poderia ser dedicado aos professores". (CP 1).

Substituir professores e outros membros da equipe gestora aparece com o menor índice (42\%) entre as alternativas; contudo, é uma das falas mais recorrentes quanto aos obstáculos que concorrem para a "quebra de rotina" do trabalho do coordenador, chamado para solucionar conflitos quase sempre associados à indisciplina dos alunos. Assim sendo, um dos maiores desafios apontados pelos coordenadores pedagógicos é a organização do tempo, para "manter o planejamento frente aos imprevistos diários da escola". No entanto, sem dúvida, dentre as atividades sob sua responsabilidade, são as burocráticas as que mais os ocupam, particularmente as relacionadas às avaliações, como é possível observar com um simples bater de olhos nos índices do Quadro 2 a seguir.

Quadro 2 - Rotina de trabalho relacionada a assuntos burocráticos/ avaliações externas

\begin{tabular}{|c|c|}
\hline $\begin{array}{l}\text { Rotina de trabalho relacionada a assuntos burocráticos/ avaliações } \\
\text { externas }\end{array}$ & Sempre \\
\hline $\begin{array}{l}\text { Realiza serviços burocráticos relacionados ao trabalho pedagógico } \\
\text { (organiza materiais solicitados pelos professores/xerox, livros, e materiais } \\
\text { para outras atividades como festas, projetos etc.). }\end{array}$ & $92 \%$ \\
\hline $\begin{array}{l}\text { Realiza serviços burocráticos relacionados à gestão (verifica diários, } \\
\text { semanários, sistema de notas online, etc.). }\end{array}$ & $92 \%$ \\
\hline $\begin{array}{l}\text { Realiza serviços burocráticos relacionados às avaliações externas (gráficos, } \\
\text { planilhas, relatórios, etc.). }\end{array}$ & $75 \%$ \\
\hline $\begin{array}{l}\text { Envolve-se na preparação de alunos/professores para as avaliações } \\
\text { externas. }\end{array}$ & $75 \%$ \\
\hline $\begin{array}{l}\text { Discussão e análise dos resultados das avaliações externas para reavaliação } \\
\text { do Projeto Político-Pedagógico da escola. }\end{array}$ & $83 \%$ \\
\hline
\end{tabular}

Fonte: Elaborado pelas autoras. 
A grande demanda de solicitações de projetos, o excesso de trabalho burocrático e ter de resolver problemas ligados a outras esferas administrativas retiram do coordenador pedagógico o tempo necessário para dedicar aos estudos e para "trabalhar melhor o atendimento individualizado a pais, alunos e professores". Como consequência, outro desafio apontado é " [...] ter de controlar a ansiedade, não demonstrando muitas vezes a insegurança que a gente sente, pois somos vistos como exemplo e o ponto de fuga dos professores" (CP 2).

Essa fala é reveladora da tensão subjetiva vivida pelo coordenador pedagógico entre corresponder às expectativas dos professores e a consciência das lacunas que se interpõem ao cumprimento do seu suposto papel de formador. Como se observa no Quadro 3, apenas 17\% auxiliam os professores, mas 67\% acompanham as atividades que envolvem "avaliação", número que se eleva (83\%) quando se trata de discutir o "progresso" da aprendizagem de determinados alunos. Desse modo, a cultura da avaliação ocupa o lugar mais alto no podium de suas reais atribuições.

Quadro 3 - Rotina de trabalho relacionada à formação e à gestão pedagógica da escola

\begin{tabular}{|l|c|}
\hline \multicolumn{1}{|c|}{$\begin{array}{c}\text { Rotina de trabalho relacionada à formação e à gestão pedagógica da } \\
\text { escola }\end{array}$} & Sempre \\
\hline $\begin{array}{l}\text { Realiza estudos/cursos para desenvolvimento da função (Coordenador } \\
\text { Pedagógico). }\end{array}$ & $42 \%$ \\
\hline Participa da formação contínua dos professores. & $58 \%$ \\
\hline Prepara atividades de formação para o HTPC. & $67 \%$ \\
\hline Auxilia os professores na elaboração de aulas e atividades. & $17 \%$ \\
\hline $\begin{array}{l}\text { Acompanha/ auxilia o trabalho dos professores/alunos (elaboração de } \\
\text { aulas/ atividades/avaliação). }\end{array}$ & $67 \%$ \\
\hline $\begin{array}{l}\text { Participa em discussôes a respeito do progresso de aprendizagem de } \\
\text { determinados alunos. }\end{array}$ & $83 \%$ \\
\hline $\begin{array}{l}\text { Participa ativamente de órgãos colegiados (Reuniões pedagógicas; } \\
\text { Conselho de classe; Conselho escolar; APM). }\end{array}$ & $100 \%$ \\
\hline
\end{tabular}

Fonte: Elaborado pelas autoras.

Chama atenção, nesse último quadro, que todos confirmam a participação "ativa" nos órgãos colegiados da escola, afinal é parte obrigatória da performance do exercício da "gestão democrática". Entretanto, o fato de que menos da metade (42\%) realiza estudos para o desenvolvimento de sua função e que meros $58 \%$ declarem participar da formação contínua de professores são indícios da suspeita de que há ainda um longo percurso a ser trilhado nessa direção. 
Apesar disso, convive no universo de representações desses sujeitos um lugar de maior importância e autoria acerca de seu papel, bem como a expectativa de que possam romper com o isolamento vivido pelos professores. É o que sugere a seguinte reflexão de uma coordenadora: "Acredito que ver a escola como um todo é um grande aprendizado e permite
uma reflexão mais ampla sobre educação. Além de poder auxiliar os
professores a trabalharem cada vez melhor com os alunos. Quando estava
em sala de aula, muitas vezes me sentia sozinha com minhas dúvidas e
dilemas sobre educação e saber que posso contribuir com a diminuição
desses dilemas faz dar um grande significado ao meu trabalho" (CP 5).

Foi nesse cenário que, em 2016/17, com o objetivo de construir mecanismos de fortalecimento da gestão democrática, três experiências de pesquisa colaborativa foram conduzidas por coordenadores pedagógicos com seus pares, professores e coordenadores de área, estes últimos de áreas específicas do currículo do Ensino Fundamental.

Dois princípios nortearam esses trabalhos: o princípio epistemológico de que o conhecimento produzido não prescinde da participação e do engajamento dos atores da escola; e o princípio político de que o sentido da pesquisa só se realiza plenamente com sua efetiva contribuição à promoção de mudanças. E, como um e outro passam necessariamente pelo exercício reflexivo, a escolha pela pesquisa-ação colaborativa na linha emancipatória descrita por Ibiapina (2008) pareceu um caminho promissor para pensar a escola na perspectiva da qualidade social da educação.

Para Silva (2009), além de determinantes externos (fatores socioeconômicos, socioculturais, financiamento, etc.), alguns indicadores do ambiente escolar precisam ser considerados na construção desse conceito, entre eles, “[...] a organização do trabalho pedagógico e a gestão da escola; os projetos escolares [...], o diálogo como premissa básica; o trabalho colaborativo e as práticas efetivas de funcionamento dos colegiados e/ou dos conselhos escolares" (SILVA, 2009, p. 224).

Pensando em envolver professores e coordenadores de área, foram planejados e desenvolvidos ciclos de reflexão (sessões reflexivas) cujas pautas referiam-se a questões sensíveis e emergentes relacionadas ao foco temático de cada um dos estudos. ${ }^{\dagger \dagger} \mathrm{A}$ ideia era de que as discussões tornassem os participantes parceiros das investigações. Para isso, a estrutura e a dinâmica dessas experiências deveriam romper com os formatos usuais de cursos, de oficinas, de capacitações, de palestras, nos quais o coordenador pedagógico é posto no lugar de um suposto saber "útil” aos professores. 
Nas sessões, a função do coordenador (pesquisador) foi a de sensibilizar e convocar os participantes a discutir aspectos problemáticos da prática, estabelecendo relações significativas com constructos teóricos a eles correspondentes. Nessa proposta, construída sobre uma base de confiança, os colaboradores foram se reconhecendo nas elaborações feitas e ampliando, aos poucos, a compreensão sobre as temáticas postas em questão.

Estava claro, desde o início, porém, que a transformação qualitativa pretendida só ocorreria se os participantes/colaboradores fossem confrontados com questionamentos que os levassem a transcender a visão de senso comum sobre as temáticas propostas. Isso porque:

Sem o apoio conceitual e teórico da investigação educativa e da reflexão sistemática e compartilhada sobre a prática, o processo de socialização do professorado e de aprendizagem com a categoria, se reproduz facilmente em seu pensamento e sua prática, os vícios, os preconceitos [...] sob a pressão onipresente da cultura pedagógica dominante e das exigências que a instituição escolar impõe (PÉREZ GÓMEZ, 1998, p. 364).

Com isso em mente, as sessões foram organizadas em torno de quatro ações reflexivas, as quais constituem diferentes momentos da pesquisa colaborativa: a) o da descrição, no qual os participantes, ao descreverem suas práticas, tomam distanciamento delas e são chamados a apresentarem as razões das escolhas feitas; b) o da informação, em que são convidados ao diálogo com aportes teóricos que ampliam e aprofundam o seu entendimento sobre as questões em pauta; c) o do confronto, momento que, a partir das reflexões realizadas sobre o material teórico e conceitual da etapa anterior, realizam um esforço de compreensão de suas práticas; d) e, por fim, o da reconstrução, momento propositivo de ações fundamentadas na reflexão crítica sobre práticas e conceitos (IBIAPINA, 2008).

Com duração de 1 hora e 30 minutos, em média, diferentes pautas, estratégias e suportes subsidiaram as reflexões como documentos escolares, textos teóricos, excertos de filmes e até poesias. O cuidado com a ambientação das sessões foi considerado aspecto importante (cadeiras nomeadas, flores na mesa, água e "mimos" para os participantes) de modo a proporcionar um clima de valorização, acolhimento e envolvimento de todos. A cada encontro, uma breve retomada das sessões anteriores foi realizada, de modo que os objetivos fossem apropriados e as discussões tomassem corpo e significado para o grupo.

Em uma das experiências, por exemplo, a coordenadora/pesquisadora deu início aos trabalhos confrontando as atribuições dos coordenadores de área ${ }^{\sharp}$ descritas no regimento escolar com aquelas que efetivamente ocupam o seu dia a dia. Muitos se mostraram surpresos, 
pois desconheciam o documento. Puderam constatar que, embora trabalhem muito, sua rotina de trabalho não é definida pela agenda de atribuições do cargo, mas pelas demandas e urgências diárias, o que os obriga a despender muito de seu tempo e energia em detrimento do trabalho pedagógico.

"Eu tenho a impressão que a gente não se aprofunda em nada porque a gente não tem certeza das nossas prioridades, então, a gente não consegue aprofundar em nada porque nem consegue dizer o que é mais importante" (Coordenador de Área 1).

"A gente faz de tudo um pouco. A gente olha as atividades que os professores mandam [...] em época de prova, tem a parte de separar algum material para o professor que pediu, às vezes a gente substitui quando falta professor [...]" (Coordenador de Área 2).

Em meio às discussões, emergiram necessidades de mudança e, dentre os pontos destacados, a "falta de tempo" foi um dos mais recorrentes entre os participantes:

"Não deu tempo de ver tudo, nunca dá, a gente programa e nunca dá" (Professor 1).

"Eu acho que o professor tinha que ter tempo também para conversar, para decidir, porque a gente conversa só no planejamento [...]” (Professor 3).

A princípio, ficou evidente que tanto os coordenadores de área como os professores não tinham muita clareza de por que isso acontece ou de que forma o trabalho colaborativo poderia auxiliá-los a reduzir esse "peso". Além disso, na tentativa de apresentarem propostas alternativas, a tendência foi reproduzirem a máxima de que para gerar "bons resultados" é importante compartilhar "boas práticas", expressões recorrentes nas "capacitações" promovidas pela rede de ensino oficial.

"Eu acho que poderíamos montar um banco de 'boas ideias', para facilitar o nosso trabalho. Porque nem sempre a gente vai lembrar de tudo [...]". (Professor 2).

Contudo, na medida em que as reflexões avançaram, a própria vivência nas sessões levou o grupo a reformular, em parte, esse entendimento. Em suas falas, começou a aparecer a necessidade de quebrar o isolamento dos professores e a consciência de que as "soluções" para suas dificuldades poderiam advir da colaboração entre os pares e não de receitas externas. Além disso, foram se dando conta da necessidade de afirmar sua autonomia para definir prioridades, organizar os tempos e os espaços e viabilizar propostas surgidas na troca de ideias entre eles. 
Para consolidar as relações entre a equipe gestora e os docentes, as condições indispensáveis apontadas foram o diálogo e o clima de confiança:

"Eu acho que tem muita coisa, que principalmente o professor poderia ajudar... tem muito professor que trabalha muito no casulo dele" (Professor 4).

"Eu acho que os professores poderiam assistir às aulas entre si, e eles se ajudarem, avaliarem, perceberem temas interdisciplinares, sentirem mais, não sei, sinceramente, se essa observação tem que ser feita por um coordenador. Eu acho que um professor tem autonomia para isso. Tiraria um pouco o peso [...]" (Professor 3).

"É isso que eu estava pensando, chegar num diálogo e chegar num nível de confiança que a gente tem com os coordenadores, como eu e o N., que é da área, de ele chegar em qualquer aula, sem precisar avisar antes, por exemplo" (Professor 4).

Da leitura atenta dos muitos depoimentos, desabafos e reflexões dos participantes, extrai-se como pontos comuns aos três estudos a situação de isolamento vivida por professores e coordenadores, em grande parte pela ausência de tempos/espaços de escuta atenta às suas angústias, às suas preocupações e aos seus projetos.

\footnotetext{
"Eu aprendi muito com as sessões, com os depoimentos dos colegas sobre as situações vivenciadas por eles dentro da escola. Sugiro que debates como esses sejam feitos, inclusive sobre outros temas para que possamos lidar de forma mais segura com as situações cotidianas" (Coordenador de Área 2).

"Eu me senti muito bem participando das sessões. Adoraria que nossos HTPC nos proporcionassem momentos de reflexão como esses" (Professor $1)$.

"O aprendizado e as trocas de experiências são um processo eterno de construção pessoal e profissional. P.S. Se os HTPCs pudessem ser nesses moldes, acredito que construiríamos uma base mais sólida na educação" (Professor 5).
}

"[é preciso] criar momentos nos HTPCs em que os professores se percebam como grupo e que o trabalho/olhar seja em grupo" (Coordenador de Área 2).

O sentimento de satisfação por terem sido valorizados e pela oportunidade de refletirem juntos não indica apenas a avaliação positiva que fizeram das sessões, mas precisa ser lido como expressão do desejo e da possibilidade concreta de ocupar os espaços e os tempos já existentes na escola - como os Horários de Trabalhos Pedagógicos Coletivos (HTPC), por exemplo - para o fortalecimento do protagonismo desses profissionais e dos vínculos de confiança indispensáveis ao exercício da gestão democrática da escola.

Sanny Silva da ROSA, Géssica Natália CAMPOS, Maria Isabel PADOVAN, Vanessa Maria Vicente UMEMURA Gestão pedagógica e qualidade social da educação: contribuições da pesquisa colaborativa em escolas de São Caetano do Sul 


\section{ALGUMAS PALAVRAS FINAIS}

A rigor, o conteúdo e o formato das sessões reflexivas relatadas no último tópico nada têm de inovador. Os primeiros registros de pesquisa-ação colaborativa remontam aos estudos do psicólogo alemão Kurt Lewin (1890-1947), na década de 1940, quando, inquieto com as razões que teriam levado milhões de judeus a aceitarem passivamente a dominação nazista na Segunda Guerra Mundial, o pesquisador procurou ouvir as pessoas não na posição de objetos de conhecimento, mas na de sujeitos, convicto de que a gênese social da pesquisa precede a sua gênese teórica. Muitas outras experiências, como as de Luria (2002), Barbier (1985), Carr e Kemmis (1988), Zeichner (1993), Stenhouse (1998), Freire (1997), Thiollent (2011), entre outros, figuram como referências dessa modalidade de investigação consolidada ao longo do século passado.

É surpreendente, lamentável e preocupante que a dinâmica das atividades propostas em nossos estudos - que supostamente deveria ser familiar à rotina das escolas públicas, orientadas que são por uma legislação que tem por princípio básico a gestão democrática - soe inusitada aos seus participantes. Assim, a primeira constatação que salta aos olhos neste trabalho é a de que o diálogo e a reflexão causam, ainda, certo estranhamento.

A segunda constatação é que, imersos em suas atividades laborais, no sentido arendtiano do termo, esses profissionais ignoram as razões que os mantêm isolados e presos à obsessiva busca por melhores desempenhos que se extingue a cada nova rodada de avaliações. Marcados por essa condição, tendem a reproduzir discursos cujos sentidos e intencionalidades caminham na contramão de concepções e valores que, intuitivamente, sustentam seus vínculos com a educação e com a escola. E isso talvez porque a tese da eficiência, disfarçada de princípio abstrato e com a aparência enganosa de neutralidade científica, lhes pareça muito "natural" e praticamente irrepreensível.

A falta de tempo para o trabalho que de verdade importa - uma das maiores queixas apontadas pelos participantes - é um dos sintomas mais visíveis da capilaridade e do poder corrosivo da concepção hegemônica de educação e do modelo McDonald's de "serviços educacionais" que atinge as escolas. Essa visão ignora o caráter artesanal do ato educativo e seu valor social como bem público. Por consequência, nega aos profissionais de educação (seja ele o professor, o coordenador pedagógico ou de área) a dimensão política e criativa de seu 
trabalho, cujo resultado só pode ser reconhecido na durabilidade da qualidade humana que for capaz de produzir.

Entretanto, dada a oportunidade e criadas as condições para que expressem o que percebem, vivem e pensam, é possível vislumbrar possibilidades que emergem de práticas que convidam os sujeitos a refletir sobre o sentido da educação que realizam e colocam em pauta a qualidade social que pretendem ajudar a construir na perspectiva do tempo. Os recortes de falas reproduzidos no último tópico deste artigo não dão conta de expressar a fecundidade e os efeitos subjetivos, ainda que incipientes, das ações conduzidas pelas profissionais/pesquisadoras nas escolas dessa rede pública de ensino. Isso nos faz pensar, como sugere Michael Apple (2018), que é preciso persistir na abertura de espaços de escuta e diálogo e na construção de mecanismos enfrentamento de projetos que sufocam os educadores, reduzem o seu trabalho ao labor e colocam em risco o próprio exercício da democracia.

Além disso, as experiências colaborativas aqui relatadas ajudam-nos a consolidar a posição de que a tarefa formativa designada aos coordenadores pedagógicos é muito diversa daquela sustentada pelos discursos axiomáticos comuns. Como coadjuvante, e não como elemento à parte ou acima de sua equipe, cabe a ele sim manter vivo e presente o enredo que articula o trabalho de todos em função de um projeto comum e constantemente negociado. $\mathrm{O}$ caráter formativo dessa tarefa só se realiza se o processo sistemático de reflexão e diálogo sobre os dilemas e os desafios interpostos na complexidade das práticas cotidianas for capaz de produzir mudanças substantivas na subjetividade das pessoas e na atmosfera em que realizam um trabalho educativo que tenha em vista a formação humana e a justiça social.

Contudo, e para que nenhum romantismo pedagógico mitigue a criticidade dessas observações finais, registramos o valor indispensável da universidade no cumprimento de seu dever de auxiliar os profissionais da escola pública a reconhecerem e a se desvencilharem das armadilhas dos discursos que os mantêm reféns de projetos que, em absoluto, não são os seus. 


\section{REFERÊNCIAS}

APLLE, Michael. The struggle for democracy in Education: lesson from social realities. New York: Routledge, 2018.

Official knowledge: democratic knowledge in a conservative age. 2. ed. New York: Routledge, 2014.

ARENDT, Hanna. A condição humana. 10. ed. Rio de Janeiro: Forense Universitária, 2001.

BALL, Stephen J.; MAGUIRE, Meg; BRAUN, Annette. How schools do policy: policy enactments in secondary schools. London; New York: Routledge, 2012.

BALL, Stephen J. The Education debate. Bristol: The Policy Press, University of Bristol, 2008.

BARBIER, René. A pesquisa-ação na instituição educativa. Rio de Janeiro: Jorge Zahar, 1985.

BAUER, Adriana. É possível relacionar avaliação discente e formação de professores?

Educação em Revista, Belo Horizonte, v. 28, n. 2, p. 61-82, jun. 2012. DOI:

http://dx.doi.org/10.1590/S0102-46982012000200004

BONAMINO, Alicia; SOUSA, Sandra Zákia. Três gerações de avaliação da educação básica no Brasil: interfaces com o currículo da/na escola. Educação e Pesquisa, São Paulo, v. 38, n. 2, p. 373-388, jun. 2012.

BRASIL. Presidência da República. Casa Civil. Discurso na sessão de instalação do Conselho Nacional de Ciência e Tecnologia. Brasília: Biblioteca da Presidência da República, 17 ago. 1996. Disponível em:

< http://www.biblioteca.presidencia.gov.br/presidencia/ex-presidentes/fernando-henriquecardoso/discursos/10-mandato/1996-1/22.pdf>. Acesso em: 14 jan. 2018.

CARR, Wilfred; KEMMIS, Stephen. Teoría crítica de la enseñanza: la investigación acción en la formación del profesorado. Barcelona: Ediciones Martínez Roca, 1988.

CHIZZOTTI, Antônio; PONCE, Branca J. O currículo e os sistemas de ensino no Brasil. Currículo sem Fronteiras, v. 12, n. 3, p. 25-36, set./dez. 2012.

CÓSSIO, Maria Fátima. Agenda transnacional e governança nacional: as possíveis implicações na formação e no trabalho docente. Revista e-Curriculum, São Paulo, v. 13, n. 4, p. 616-640, out./dez. 2015.

DRABACH, Neila Pedrotti; MOUSQUER, Maria Elizabete Londero. Dos primeiros escritos sobre administração escolar no Brasil aos escritos sobre gestão escolar: mudanças e continuidades. Currículo sem Fronteiras, v. 9, n. 2, p. 258-285, 2009. 
FREIRE, Paulo. Pedagogia da autonomia: saberes necessários à prática educativa. 33. ed. São Paulo: Paz e Terra, 1997.

FREITAS, Luiz Carlos de. Os reformadores empresariais da educação e a disputa pelo controle do processo pedagógico na escola. Educação \& Sociedade, Campinas, v. 35, n. 129, p. 1085-1114, dez. 2014.

FUNDAÇÃO SEADE. Portal de Estatísticas do Estado de São Paulo. 2017. Disponível em: <http://produtos.seade.gov.br/produtos/projpop/index.php>. Acesso em: 15 jan. 2018.

GARCIA, Paulo Sérgio et al. Desempenho escolar: uma análise do IDEB das cidades da Região do Grande ABC. In: GARCIA, Paulo Sérgio; PREARO, Leandro. (Orgs.). Avaliação da educação escolar no Grande ABC Paulista: primeiras aproximações. São Paulo: Plêiade, 2015a. p. 41-70.

GARCIA, Paulo Sérgio et al. Formação, atuação e formas de gestão dos diretores de escola da Região do ABC. In: GARCIA, Paulo Sérgio; PREARO, Leandro. (Orgs.) Avaliação da educação escolar no Grande ABC Paulista: primeiras aproximações. São Paulo: Plêiade, 2015b. p. 149-181.

GARCIA, Maria M. Alves; ANADON, Simone Barreto. Reforma educacional, intensificação e autointensificação do trabalho docente. Educação \& Sociedade, Campinas, v. 30, n. 106, p. 63-85, jan./abr. 2009.

GATTI, Bernadete Angelina; BARRETO, Elza Siqueira de Sá; ANDRÉ, Marli E. D. Afonso. Políticas docentes no Brasil: um estado da arte. Brasília: Unesco, 2011. p. 31-48.

HYPOLITO, Álvaro Moreira; VIEIRA, Jarbas dos Santos; LEITE, Maria Cecília Lorea. Currículo, gestão e trabalho docente. Revista e-Curriculum, São Paulo, v. 8, n. 2, p. 1-16, ago. 2012.

IBIAPINA, Ivana Maria Lopes de Melo. Pesquisa Colaborativa: Investigação, formação e produção de conhecimentos. Brasília: Líber Livro, 2008. [Série Pesquisa, n. 17].

LIMA, Licínio C. A escola como organização educativa. São Paulo: Cortez, 2001.

LURIA, Alexander Romanovich. Desenvolvimento cognitivo. 3. ed. São Paulo: Ícone, 2002.

MARIN, Alda Junqueira; GIOVANNI, Luciana Maria. Formação de professores para o início da escolarização: fragilidades. InterMeio, Campo Grande, v. 19, n. 38, p. 52-68, jul./dez. 2013.

NÓVOA, António. Governing without governing - The formation of a European educational space. In: APPLE, Michael W.; BALL, Stephen J.; GANDIN, Luis Armando. (Eds.). The Routledge International Handbook of the Sociology of Education. Abingdon; Oxon: Routledge, 2009. p. 264-273. 
PECK, Jamie; TICKELL, Adam. Neoliberalizing space. Antipode, Oxford, Malden, p. 380404, 2002. DOI: https://doi.org/10.1111/1467-8330.00247

PÉREZ GÓMEZ, Ángel I. A função e formação do professor/a no ensino para a compreensão: diferentes perspectivas. In: SACRISTÁN, Gimeno José; PÉREZ GÓMEZ, Ángel I. (Orgs.). Compreender e transformar o ensino. 4. ed. São Paulo: Artmed, 1998. p. 353-375.

PONCE, Branca J.; ROSA, Sanny S. da. Políticas curriculares do Estado Brasileiro, trabalho docente e função dos professores como intelectuais. Revista Teias, Rio de Janeiro, v. 15, n. 39, p. 43-58, 2014.

RITZER, George. (Ed.). McDonaldization: the reader. 3. ed. California: Pine Forge Press; London: SAGE Publ. Ltd., 2010.

ROSA, Sanny S. da. Reformas educacionais e pesquisa: as políticas "em cena" no Brasil e na Inglaterra. Revista e-Curriculum, São Paulo, v. 9, p. 1-28, 2012.

SACRISTÁN, Gimeno José. A educação que ainda é possível: ensaios sobre uma cultura para a educação. Porto Alegre: Artmed, 2007.

SHIROMA, Eneida O. A formação do professor-gestor nas políticas de profissionalização. Revista e-Curriculum, São Paulo, v. 7, n. 2, p. 1-20, ago. 2011.

SILVA, Maria Abádia. Qualidade social da educação pública: algumas aproximações. Cadernos Cedes, Campinas, v. 29, n. 78, p. 216-226, maio/ago. 2009.

SORDI, Maria Regina Lemes de; VARANI, Adriana; MENDES, Geisa do Socorro C. Vaz. (Orgs.). Qualidade(s) da Escola Pública. Reinventando a avaliação como resistência. Uberlândia, MG: Navegando Publicações, 2017. Disponível em: $<$ https://www.editoranavegando.com/qualidade-s-da-escola-publica $>$. Acesso em: 14 jan. 2018.

SOUZA, Vera Lúcia Trevisan de; PLACCO, Vera Maria Nigro de Souza. O coordenador pedagógico, a questão da autoridade e da formação de valores. In: ALMEIDA, Laurinda Ramalho de; PLACCO, Vera Maria Nigro de Souza. (Orgs.). O coordenador pedagógico e questões da contemporaneidade. 3. ed. São Paulo: Loyola, 2009. p. 25-39.

STENHOUSE, L. La investigación como base de la ensenanza. 1998. Disponível em: $\langle$ http://www.terras.edu.ar/biblioteca/1/CRRM_Stenhouse_Unidad_1(1).pdf $>$. Acesso em: 15 nov. 2018.

TAVARES, Luana Serra Elias. Autoria ou reprodução? O cotidiano de professores coordenadores no contexto do programa Ler e Escrever. Santos. 2012. 230 f. Dissertação (Mestrado em Educação) - Universidade Católica de Santos, Santos, 2012.

THIOLLENT, Michel. Metodologia da pesquisa-ação. 18. ed. São Paulo: Cortez, 2011. 
WERLE, Flávia O. Correa; SCHEFFER, Lisandra Scheneider; MOREIRA, Marilan de Carvalho. Avaliação e Qualidade Social da Educação. ETD - Educação Temática Digital, Campinas, v. 14, n. 2, p. 19-37, 2012.

WILKINSON, Gary. McSchools for Mc World? Mediating global pressures with a McDonaldizing education policy response. In: RITZER, George. (Ed.). McDonaldization: the reader. 3. ed. California: Pine Forge Press; London: SAGE Publ. Ltd., 2010. p. 150-158.

ZEICHNER, Kenneth M. A formação reflexiva de professores: ideias e práticas. Lisboa: Educa, 1993.

\footnotetext{
* Os estudos a que se refere este artigo abrigam-se no projeto do grupo de pesquisa Gestão Democrática $e$ Qualidade Social da Educação Básica da Universidade Municipal de São Caetano do Sul (USCS).

† No Brasil, o Instituto Ayrton Senna, Itaú Social e Fundação Lemann são exemplos de "parceiros” do Estado na formulação e no monitoramento de políticas públicas educacionais, com amplo apoio de empresas privadas de diferentes setores da economia.

\$ Thomas J. Peters e Robert H. Waterman Jr., administradores de empresa e autores do best-seller In Search of Excelence, editado em português, em 1983, sob o título Vencendo a crise (Editora Harbra).

$\S$ A expressão “delivery chain" (cadeia de entregas) foi cunhada por Michael Barber para designar a sistemática utilizada para produzir resultados e atingir as metas do governo para o setor público (BALL; MAGUIRE; BRAUN, 2012, p. 74-75).

** Em 2010, o município de São Caetano do Sul figurava em $1^{\circ}$ lugar no ranking nacional (IDHM de 0,862, em uma escala que varia de 0 a 1), enquanto o IDHM médio da região era de aproximadamente 0,792 , conforme estudo de Garcia et al. (2015a).

$\dagger$ Os três estudos do grupo tiveram como eixo a relação entre gestão democrática e qualidade social da educação, a partir das seguintes temáticas: educação integral, educação em direitos humanos e formação de professores.

\# O Coordenador de Área, na Rede Municipal de São Caetano do Sul, auxilia o Coordenador Pedagógico oferecendo apoio pedagógico aos professores em áreas específicas do currículo.
} 